\title{
Investigation on the Implementation Status of the Graduate National Scholarship System in China
}

\author{
Yan-hua CHEN ${ }^{1, ~ *}$ and Yue $\mathrm{LI}^{1}$ \\ ${ }^{1}$ Graduate school of Jiangxi Science \& Technology Normal University, \\ Nanchang, 330013, P.R. China \\ *chenyh@jxstnu.edu.cn
}

Keywords: Graduate, National scholarship system, Investigation.

\begin{abstract}
Provisional graduate national scholarship system has been set up by Chinese Ministry of finance and Ministry of education, whose intentions are to encourage and aid the outstanding graduates, and enable them to try their best to study and actively devote themselves to academic researches. Many people are wondering whether the policy has played a favorable part in cultivating graduate students after three years of implementation. In this paper, we investigated the implementation status of the graduate national scholarship system through questionnaire and interview in six universities in central China's Jiangxi Province. The investigation showed there were some problems in the implementation of the system. And we gave some countermeasures and suggestions that would be reference for improvement of the system.
\end{abstract}

\section{Introduction}

According to the spirits of the National Outline for Medium- and Long-Term Educational Reform and Development (2010-2020), the central government decided to establish a national scholarship for postgraduates to reward all-round excellent ones in institutions of higher education. Thus, Ministry of Finance and the Ministry of Education specially formulated the Interim Measure for the National Scholarship Management of Graduates, which had been implemented on September $1^{\text {st }}, 2012[1]$. With good original intention, the policy mainly commits to reward and fund excellent postgraduates so that they can exert their greatest potential as well as take an active part in academic researches. Moreover, it also will set up a new platform for institutions to evaluate students' professional level and objectively contributes to the expansion of campus academic flaw and the reinforcement for the awareness of students' self-learning. Therefore, the policy of the National Scholarship for postgraduates functions both in students and universities. In view of the different conditions of every university, ways of implementing the policy might not be the same. Each of them would do this by combining its own real conditions which might lead to a phenomenon that based on the same policy, universities might present different evaluating ways from each other when evaluating the National Scholarship for postgraduates. Since the implementation of the national scholarship for graduates in 2012, there were little reports about those problems, which included the effect and influence of it. The article is to analyze the current conditions through questionnaire and interview, and analyze how to enhance the influence of the national scholarship and motivation for studying. Research achievements would be finally used as a reference in perfecting this scholarship system so that it could exert its maximum effect in future. 


\section{Research Methods}

During the days from February to December in 2014, we had investigated six universities in central China's JiangXi Province. With the specific implementations, on the one hand, we gave out 850 questionnaires in total to postgraduates in the schools in order to investigate their conditions. Among which 300 questionnaires were sent to JiangXi University of Finance and Economic, 200 to JiangXi Agricultural University, 150 to East China JiaoTong University and DongHua University of Science and Technology respectively and both JiangXi Normal University of Science and Technology and Nanchang Aviation University were 100, eventually 757 usable questionnaires were adopted. On the other hand, we communicated with postgraduate tutors and relevant personal such as judge of reward. After dates collection from questionnaires and interviews, we analyzed them by SPSS software.

\section{Problems}

According to the research analysis, in general, each university implemented in accordance with the content of the graduate national scholarship policy and had much effect, moreover, in a certain degree, promoting and encouraging students devote to study and academic research. More than ninety percent of postgraduates all expected to get national scholarship. They not only had the strong appetite to obtain that scholarship, but also almost sixty percent of graduates would like to reduce other extracurricular activities to get it, and spend more time on studying and working on academic research, thus it's no doubt that graduates were spurred on studying and conducting research, as a result of achieving the significance of awarding national scholarship and boosting training of outstanding graduates and making constantly achievements in scientific research. But similarly, during the course of better implement national scholarship, different universities also existed some problems of common and individual characters, it's essential for us to improve the national policies better and make efforts to do the things on the right direction.

\section{The First Problem: Postgraduates Were Not Acquainted with the Policies}

Although most postgraduates all desired to get national scholarship, but only a few graduates understood this policy generally. Studies showed that eighty percent of graduates only knew the amount of national scholarship, but not awarding of the purpose and the meaning of scholarship and had no acquaintance with the detail of national scholarship policy. Almost sixty percent graduates who had no idea of whether or not, the family conditions were bound to be considered as the national scholarship handed out. So when awarding national scholarship, most students were just blind to apply for it. We supposed that two major reasons lead to the phenomenon. Firstly, the university was not sufficient to publicize and explain the national scholarship policy, and the university showed the leading position all the time, but lacking of mind to place graduates into active participation of the object during the awarding process. Secondly, graduates also had a weak sense to participation, they not cleared and lacked of the mind as the main object during the process.

\section{The Second Problem: Student's Cadres Have Superiority in Awarding National Scholarship}

About seventy percent of students got the upper hand in the process of awarding national scholarship. According to the graduate national provisional scholarship system stipulated, one of the requirements is that "success in studying, splendid in capacity of scientific research, outstanding in development potential, but it not require that graduates need active in class or in student organization. From this point, when 
surveyed in awarding national scholarship, the class leader "get the upper hand" was not conform to the general phenomenon. We considered that was rational, although the phenomenon was not accord with temporal method. Postgraduate education is the highest level in schooling, so it stands important task of cultivating outstanding innovation talents. Thus we could not just see from graduates' research and scientific aptitude. In the same way, we also attach importance on cultivating the ability of society and life, only such this students can exert his largest into extreme, only such this students can understand life, society and contribute his strength to society.

\section{The Third Problem: The Evaluations System Does Not Really Follow the Criterion}

The origin of national graduate scholarship was with a good intention, but some problems were raised during implementing. Only 25\% students thought the evaluations system was based on openness and fairness, which demonstrated the policy, was implemented according to the criterion. There lied behind some immoral activities, such as make sorts of ways to bribe the related personnel. The evaluations systems implemented by some universities were neither open nor transparent, therefore such suspicion was caused among students, or actually, there were some illegal deals.

\section{The Fourth Problem: Quantitative Evaluations are Disputed}

The six universities we have surveyed overall took quantitative evaluations to implement the national graduate scholarship while $60 \%$ students believed such measures were unfavorable for the personal and diverse development of graduate students. With so many students in disagreement with quantities evaluations, we should continuously explore to find what the best way for the evaluations was.

\section{The Fifth Problem: The Function of National Graduate Scholarship Is Not So Effective}

The original intentions of national graduate scholarship were to solve difficulties in students' livelihood, encourage students to work harder and pay their attention to academic research, inspire students' potentials, and then cultivate the educated graduate students. But, less than $10 \%$ students believed the national graduate scholarship could attain its intentions. The majority of students thought implementing the national graduate scholarship might yield some negative influences in some universities. For example, to get a scholarship, a part of students wrote nonsensical academic papers, degrading academic atmosphere. Some students took illegal measures to bribe the teachers in charge, to obtain higher scores. No matter open or secretive, Strife among students, cause's disharmony. These negative phenomena going against the intentions of national graduate scholarship also went against our wills. And we should take measures to precaution it.

\section{Countermeasures and Suggestions}

\section{Improving Students' Participation and Fully Reflecting the Fairness and Justice}

The fundamental guarantee of carrying out the graduate national scholarship policy are fairness and justice. Schools are supposed to require students in each class to learn about Provisional graduate national scholarship system together before selection, thus, students could know about the requirements and details as far as possible. This way would not only let graduate students learn more about national scholarship but also increase their identification with the measures, and finally make them participate positively. Besides, a symposium should be conducted by school before the selection, by this means, schools solicit opinions from the teachers and students through 
questionnaires and formulate regulations preliminarily. Schools eventually formulate the selection process and regulations according to the detail requirements of Provisional graduate national scholarship system. Then schools should distribute the regulations to students and take a public poll. Their feedback would be useful for supplement and modification. At last, the regulations which coincides public opinion and are operable are formed [2].

\section{Setting up Graduate Student Individual Scholarships and Pay Attention to Diversified Development}

In accordance with the fourth regulation of Provisional graduate national scholarship system, the standard national scholarship of each graduate student was 20,000 yuan every year. However, more than half graduate students considered that the national scholarship could not meet the needs because only 35,000 students could get the scholarship which accounted only for 1.3\% (on the basis of the 10th item of the statistical information which was released by the State Statistics Bureau on February 24, 2014). In addition, the big economic benefits would inevitably lead to competition and then the negative impact of competition also gradually revealed. By increasing the individual scholarships and closing the gap between the amount of money, the scholarship would play a role in positive guidance and motivation, and promote benign competitions between students [3]. In hence, we suggested that the amount of national scholarship ought to be divided properly if there was no extra input in this area. Part of the money could be set up for individual scholarship but the most part of the amount was ensured for the regular national scholarship. It is necessary to cultivate the graduate students' special quality and ability in this era of knowledge economy. Individual scholarship was intended to motivate the graduate students' specialties and encourage them to turn to diversified development [4]. This kind of scholarship could involve several aspects like social practice, stylistic expertise, social work, vocational skills, moral trait, and many other aspects of the awards. By this means, the number of graduate student who could get national scholarship might be increased. And also, it improved the student' integrated development objectively instead of being confined to academic research and ignoring development of other aspects.

\section{Publicize and Standardize the Selection Rules}

Generally, colleges and universities adopted the two stage management system by school and academy. It required that the principle of combination of universality and particularity must be followed in the process of graduate national scholarship selection. That was to say, the school made the major principle and the academies developed different selection rules according to their own characteristics. Then those selection principles should be institutionalized and not allowed to change casually. But in the case of serious problems in the process of selection, the academy should reflect to the school. Finally the open and standard selection principle would be formed. The process of selection was not up to school or academy but the selection system.

\section{Emphasizing the Quality of Scientific Research Product's Evaluation}

In order to avoid that the students spend lots of time to create meaningless paper, at least one of the scholarship evaluation committee must be a prestigious teacher in the certain field. And the teacher should audit and certificate the quality of thesis which students used to apply for scholarships strictly regardless of the man-made factors. Students were supposed to be encouraged to publish high level paper. The behavior of publishing papers only for quantity without considering about the quality should be 
avoided [4].

\section{Establishing a System for Scholarship Supervision}

At present, there was no supervision on how the graduate students used the scholarship. In fact, recently, some graduates immediately treat friends to dinner or entertainment activities after obtaining the scholarship instead of making a plan for study or basic life expense. What's more, some other students used the money to purchase luxury mobile phones and laptops and so on. The behaviors above not only don't follow the intention of allocating scholarship but more seriously make bad influence between students. It was proposed that government or schools should establish monitoring system on national scholarship awarded, and rules must be made to create a good scholarship environment, on the other hand, the use of the scholarship should be in line with the original purpose of the establishment of national scholarship.

\section{Discussion}

We learned a lot from the investigation about the implementation of national scholarship for graduate in six universities of central China's Jiangxi Province. Firstly, the most success in postgraduate education of our country was that the establishment of national scholarship for graduate had unprecedented increasing the graduate student's interest in study and research of science. Secondly, as a whole, each university insisted on the principle of justice, equity and science in the process of national scholarship selection which received good results, even though there were some bad habits in the implementation of national scholarship for graduate policy. Finally, Provisional graduate national scholarship system could not consider every aspect for it carried out only three years which started from September, 2012. I believed government's relevant departments would continue to practice and innovations, and eventually improving the system, thus make the most use of graduate national scholarship.

\section{Acknowledgement}

This research was funded by "Twelfth Five Year Plan" of Jiangxi Province Education Science (NO:13YB157).

\section{References}

[1] L.Yang, Establishment of provisional graduate national scholarship system(In Chinese).Guangm. Dai. 23(2012)162-164.

[2] Z.D.Liao, Analysis of the advantages and disadvantages of the reform of the graduate scholarship system (In Chinese).Edu. Explo. 3(2008)46-48.

[3] F.Y.Chang, H.Huang, Reform and exploration of the evaluation system of graduate scholarship system (In Chinese). Edu. Chin. After-sch., 9 (2012) 20-21.

[4] E. Li, L.Liu, Consideration on the current graduate scholarship system (In Chinese). Chi. Elec. Pow. Edu. 122(2008), 138-139. 